\title{
Determining salt concentrations for equivalent water activity in reduced-sodium cheese by use of a model system
}

\author{
J. Grummer and T. C. Schoenfuss ${ }^{1}$ \\ Department of Food Science and Nutrition, University of Minnesota, St. Paul 55108
}

\begin{abstract}
The range of sodium chloride (salt)-to-moisture ratio is critical in producing high-quality cheese products. The salt-to-moisture ratio has numerous effects on cheese quality, including controlling water activity $\left(\mathrm{a}_{\mathrm{w}}\right)$. Therefore, when attempting to decrease the sodium content of natural cheese it is important to calculate the amount of replacement salts necessary to create the same $a_{w}$ as the full-sodium target (when using the same cheese making procedure). Most attempts to decrease sodium using replacement salts have used concentrations too low to create the equivalent $\mathrm{a}_{\mathrm{w}}$ due to the differences in the molecular weight of the replacers compared with salt. This could be because of the desire to minimize off-flavors inherent in the replacement salts, but it complicates the ability to conclude that the replacement salts are the cause of off-flavors such as bitter. The objective of this study was to develop a model system that could be used to measure $\mathrm{a}_{\mathrm{w}}$ directly, without manufacturing cheese, to allow cheese makers to determine the salt and salt replacer concentrations needed to achieve the equivalent $\mathrm{a}_{\mathrm{w}}$ for their existing full-sodium control formulas. All-purpose flour, salt, and salt replacers (potassium chloride, modified potassium chloride, magnesium chloride, and calcium chloride) were blended with butter and water at concentrations that approximated the solids, fat, and moisture contents of typical Cheddar cheese. Salt and salt replacers were applied to the model systems at concentrations predicted by Raoult's law. The $\mathrm{a}_{\mathrm{w}}$ of the model samples was measured on a water activity meter, and concentrations were adjusted using Raoult's law if they differed from those of the full-sodium model. Based on the results determined using the model system, stirred-curd pilot-scale batches of reduced- and full-sodium Cheddar cheese were manufactured in duplicate. Water activity, $\mathrm{pH}$, and gross composition were measured and evaluated statistically by linear mixed model. The model system method accurately
\end{abstract}

Received March 11, 2011.

Accepted May 7, 2011.

${ }^{1}$ Corresponding author: tschoenf@umn.edu determined the concentrations of salt and salt replacer necessary to achieve the same $\mathrm{a}_{\mathrm{w}}$ as the full-sodium control in pilot-scale cheese using different replacement salts.

Key words: sodium, cheese, water activity, salt replacer

\section{INTRODUCTION}

Dietary sodium is a key contributor to the development of hypertension in humans, which can be a precursor to cardiovascular disease in at-risk individuals (Adrogué and Madias, 2007; Taormina, 2010). Cheese is a major contributor to sodium in the diet (Grocery Manufacturers Association, 2008). Cheddar cheese contains approximately $620 \mathrm{mg}$ of sodium/100 g, which equates to, in a 30-g serving, approximately $8 \%$ of the US FDA's daily recommended value (21 CFR 101.9; FDA, 2011; USDA, 2011). A report by the Center for Science in the Public Interest, citing data on the contribution of packaged food sources to the US diet, listed cheese as the second largest contributor of sodium (Jacobson, 2005). Recent public health attention to the causes of cardiovascular disease has generated interest in reducing the sodium content of natural cheeses, and the National Sodium Initiative is requesting a reduction of sodium in Cheddar to $<600 \mathrm{mg} / 100 \mathrm{~g}$ by 2014 (NYCHealth, 2011).

Reducing sodium chloride (salt) use in natural cheese is difficult because salt contributes to flavor, controls starter culture activity during manufacturing, influences the syneresis of moisture from curd, and affects the activity of enzymes and microorganisms during aging (Guinee, 2004). When the amount of salt is decreased in cheese, the use of replacement salts, including those containing magnesium, calcium, or potassium, has been investigated (Lindsay et al., 1982; Fitzgerald and Buckley, 1985; Aly, 1995; Reddy and Marth, 1995; Katsiari et al., 1997, 2001). The purpose of replacement salts is to maintain a "salty" taste and to control microbial and enzymatic stability by maintaining the water activity $\left(\mathbf{a}_{\mathrm{w}}\right)$. The majority of studies did not use replacement salts at levels that would create the same $a_{w}$ as in a full-sodium cheese with the same cheese making proce- 
dure. This could be due to the difficulty in predicting the amount to use to create equivalency or because these salts have been implicated in causing bitter and metallic off-flavors (Lindsay et al., 1982; Fitzgerald and Buckley, 1985). In either case, conclusions about the usefulness of the replacement salts in sodium reduction in cheese are confounded by the fact that the $\mathrm{a}_{\mathrm{w}}$ would be different between the cheeses, and this in itself could result in bitterness due to differences in biochemical reactions.

The measurement of $\mathrm{a}_{\mathrm{w}}$ is a means to determine the chemical potential of water, which is related to the microbial and enzymatic stability of a food (Rahman and Salani, 2009). Water activity is defined as the vapor pressure of water above a food relative to that of the vapor pressure above pure water, also termed the equilibrium relative humidity (Rahman and Salani, 2009). The factors contributing to the equilibrium relative humidity are the interactions of water molecules with solutes. Because the formulas of semi-solid foods are complex, and because food undergoes processes such as heating and drying, most food is multi-component and multi-phasic. Consequently, predicting $\mathrm{a}_{\mathrm{w}}$ is problematic because the relationship between moisture content and $\mathrm{a}_{\mathrm{w}}$ is not linear. Numerous models are designed to predict the $\mathrm{a}_{\mathrm{w}}$ of solid foods with various moisture levels (Lewicki, 1997, 2009). In most cases, the molecular weight of solutes in the food plays a role in the model, as it affects molality. At equivalent mass, lower molecular weight compounds contain more molecules than higher molecular weight compounds, which results in a greater $\mathrm{a}_{\mathrm{w}}$-lowering effect. Some predictive models are based on assumptions, whereas others were empirically developed for particular food products or categories (Lewicki, 2009; Rahman and Salani, 2009; Roa and Tapia, 1998). Therefore, it is not possible to determine if predicted $a_{\mathrm{w}}$ values are representative of the food without producing experimental product.

For these reasons, predicting $\mathrm{a}_{\mathrm{w}}$ in a finished product is difficult. As a result, conclusions about the effect of sodium replacers on flavor and texture in the reducedsodium cheese in previous studies are clouded by the fact that the $\mathrm{a}_{\mathrm{w}}$ was most likely different from that of the full-sodium control. Because $\mathrm{a}_{\mathrm{w}}$ in young cheese is attributed mainly to the salt content (Guinee, 2004), deviations in $\mathrm{a}_{\mathrm{w}}$ from control in reduced-sodium cheese would be equivalent to the salt-to-moisture ratio $(\mathbf{S} / \mathbf{M}$, a strong predictor of cheese quality) being different from that of a full-sodium cheese. Cheese makers in the United States typically target an S/M of 4.5 to $5.5 \%$ to produce high-quality cheese (Lawrence et al., 1993). Agarwal et al. (2011) reported the mean sodium level in commercial US Cheddar cheese to be $615 \mathrm{mg} / 100 \mathrm{~g}$. This would equate to a salt content of approximately
$1.5 \%$, or an $\mathrm{S} / \mathrm{M}$ of 4.3 to 4.0 if the moisture ranged from 35 to $38 \%$.

Manufacturing cheese to test salt replacer concentrations to create equivalent $\mathrm{a}_{\mathrm{w}}$ can be time-consuming and expensive. We hypothesized that a model system could be developed to determine the appropriate concentrations and eliminate the need for experimental cheese manufacturing. The objective of this study was to develop a model system that could be used to measure $\mathrm{a}_{\mathrm{w}}$ directly, without manufacturing cheese, to allow cheese makers to determine the salt and salt replacer concentrations needed to achieve the equivalent $a_{w}$ to that of their existing full-sodium control formula.

\section{MATERIALS AND METHODS}

\section{Materials}

Premier Potassium Chloride 8799 (K; Cargill Inc., Minneapolis, MN), Modified Potassium Chloride 14510 (MK; Nu-Tek Products Inc., Minnetonka, MN), magnesium chloride, 6-hydrate 5956-06 (MG; Mallinckrodt Baker Inc., Phillipsburg, NJ), calcium chloride, dihydrate, granular 4616-06 (C; Mallinckrodt Baker Inc.), Top-Flo Evaporated Salt (N; Cargill Inc.), $45 \%$ reduced-sodium sea salt SS45 (S; A and B Ingredients, Fairfield, NJ), all-purpose flour (Pillsbury BEST Flour, The J. M. Smucker Co., Orrville, OH), and salted butter (Land O'Lakes Inc., St. Paul, MN) were used to prepare model systems. All chemicals were Food Chemicals Codex or United States Pharmacopeia grade.

\section{Determination of Salt and Salt Replacer Concentrations}

Raoult's law was used to calculate concentrations of salt and replacement salts:

$$
a_{w}=\gamma_{s} X_{\text {water }}=\gamma_{s} \frac{n_{\text {water }}}{n_{\text {water }}+n_{\text {solutes }}},
$$

where $\gamma_{s}=$ activity coefficient, $X=$ mole fraction, and $n=$ number of moles. An activity coefficient of 1 was used. Typical Cheddar cheese values of $1.6 \%$ salt and $36.8 \%$ moisture (wt/wt) were used as the values for the full-sodium control, and Raoult's law predicted an $\mathrm{a}_{\mathrm{w}}$ of 0.974 using those values. For reduced-sodium treatments, excluding the $\mathrm{S}$ treatment, a $53 \%$ salt reduction was used as the target, which equates to $300 \mathrm{mg}$ of sodium/100 g of sample. The amount of salt replacer (K, MK, MG, or C) needed to equal the same $\mathrm{a}_{\mathrm{w}}$ as the full-sodium target (0.974) was calculated using Raoult's law. For the $\mathrm{S}$ treatment, information provided by the manufacturer was used to calculate an equal concen- 
tration of solutes as the control treatment. It was not possible to calculate concentrations of MK because the percentage formula of all the solutes in the product was not known. Therefore, the predicted concentrations were based on analogous $\mathrm{K}$ concentrations.

\section{Preparation of Model Cheese Systems}

The general scheme for model system preparation is outlined in Figure 1. All-purpose flour and salt plus salt replacer were dry blended before butter and water were added to achieve $36.8 \%$ moisture and $36 \%$ fat (wt/wt). Moisture from the flour, butter, salt, and salt replacers was taken into account when formulating. Ingredients were blended in a 236.6-mL cup on an Osterizer 12 Speed Blender (Sunbeam Products Inc., Boca Raton, $\mathrm{FL}$ ) at high speed for approximately $45 \mathrm{~s}$ in 5 -s intervals until uniform. The $\mathrm{a}_{\mathrm{w}}$ of the model cheeses were measured with an Aqua Lab 3TE $\mathrm{a}_{\mathrm{w}}$ meter (Decagon Devices, Pullman, WA) at $23^{\circ} \mathrm{C}$. If the difference in $\mathrm{a}_{\mathrm{w}}$ between the reduced-sodium and the full-sodium treatments was greater than 0.006 , the absolute value of the difference was subtracted from 0.974 if the $\mathrm{a}_{\mathrm{w}}$ was higher than control and added to 0.974 if it was lower. The new reference $a_{w}$ was used in Raoult's law in place of 0.974 to determine the new salt replacer concentration needed to achieve equal $\mathrm{a}_{\mathrm{w}}$ to control. The new salt replacer concentrations were blended into a new model system, the formula was adjusted to achieve the same moisture and fat targets, and $\mathrm{a}_{\mathrm{w}}$ was measured to determine if the 0.974 target was achieved. This process was repeated until equivalent $\mathrm{a}_{\mathrm{w}}$ was achieved.

\section{Cheese Making}

A full-fat, stirred curd Cheddar cheese procedure was used at the University of Minnesota-Twin Cities pilot plant under the guidance of the head cheese-maker. Once the desired titratable acidity was reached for salting, curd was weighed and divided into treatment groups, which were salted using the determined salt and salt replacer concentrations from the model systems. For treatments in which models were not created $(\mathrm{S} / \mathrm{K}$, $\mathrm{S} / \mathrm{MK}, \mathrm{SS} / \mathrm{MG}$ ), the amounts used in cheese making were calculated by applying the modifications required in $\mathrm{S}$ (for the $\mathrm{S}$ component) and $\mathrm{N} / \mathrm{MG}$ (for the $\mathrm{MG}$ component) during model testing. Salt and salt replacer was added in 3 additions, at 5 -min intervals, to either 13.6 or $27.3 \mathrm{~kg}$ of drained curd in individual plastic containers with drain holes. To compensate for the loss expected during salting and pressing, concentrations of salt and salt replacer targeted for the final cheese were multiplied by 1.56. Curd was manually stirred during the salting intervals to prevent matting and then trans- ferred to cheesecloth-lined, 9.1-kg, Wilson-style cheese hoops and pressed overnight at $276 \mathrm{kPa}$. After removal from hoops, blocks were vacuum packaged. Water activity of the 9.1-kg blocks was measured after $1 \mathrm{wk}$ of refrigerated storage at 4 to $5^{\circ} \mathrm{C}$. Cheese making was replicated on $2 \mathrm{~d}$ with different lots of milk.

\section{Compositional Analysis}

Fat and ash were determined following standard methods $18.8 \mathrm{~A} 2 \mathrm{c}$ and $18.4 \mathrm{~A}$, respectively (Richardson, 1985). Ash was measured after step 18.4A3d. Moisture content was determined using a vacuum oven following standard method 15.111 (Wehr and Frank, 2004). $\mathrm{pH}$ was measured by using an Acorn $\mathrm{pH} 6$ Meter (Oakton Instruments, Vernon Hills, IL) with an Orion 8172BNWP Ross Sure-Flow pH electrode (Thermo Fisher Scientific Inc., Waltham, MA). Total protein (nitrogen $\times 6.38$ ) was determined by using a TruSpec N spectrometer (Leco Corp., St. Joseph, MI) based on the Dumas method of combustion. Sodium, potassium, magnesium, and calcium contents were measured

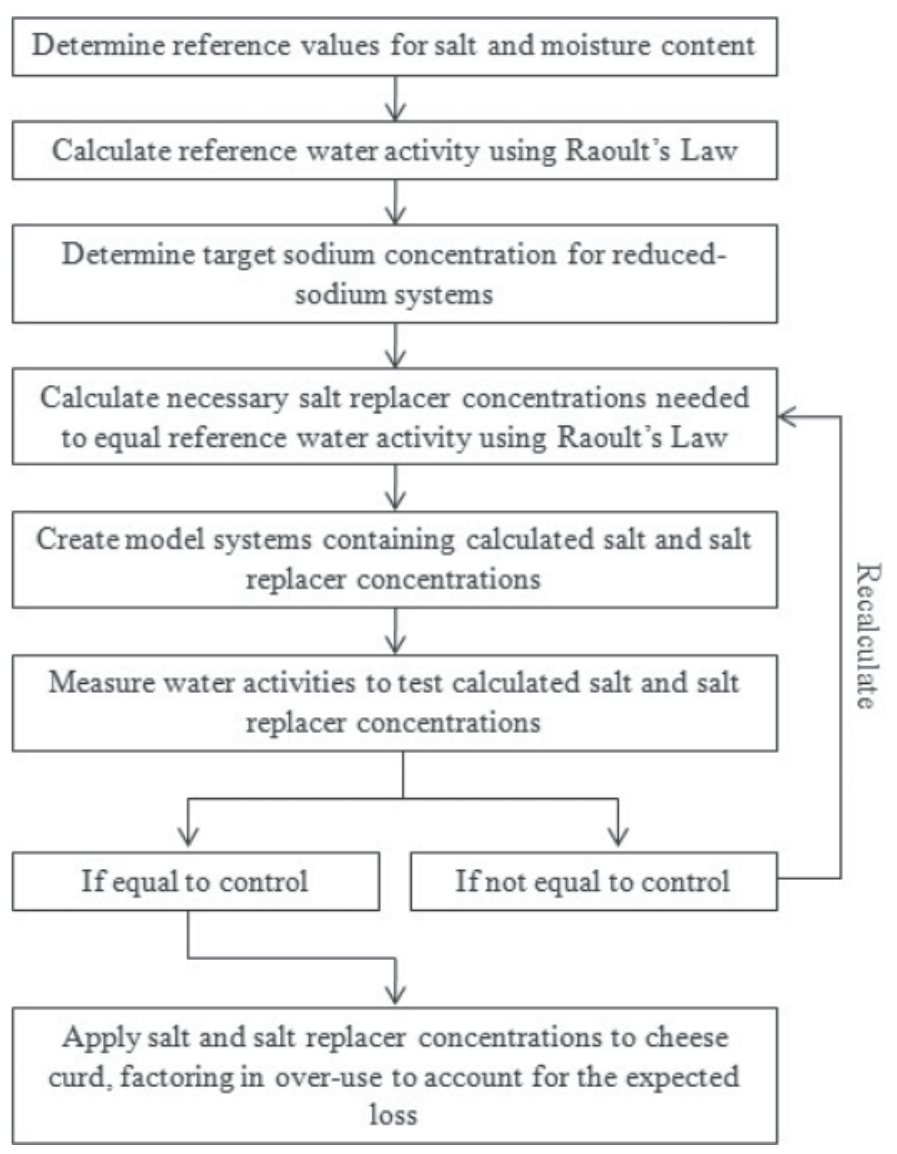

Figure 1. General scheme of salt and salt replacer concentration determination. 
Table 1. Salt and salt replacer concentrations predicted using Raoult's law to create equivalent water activity in model systems

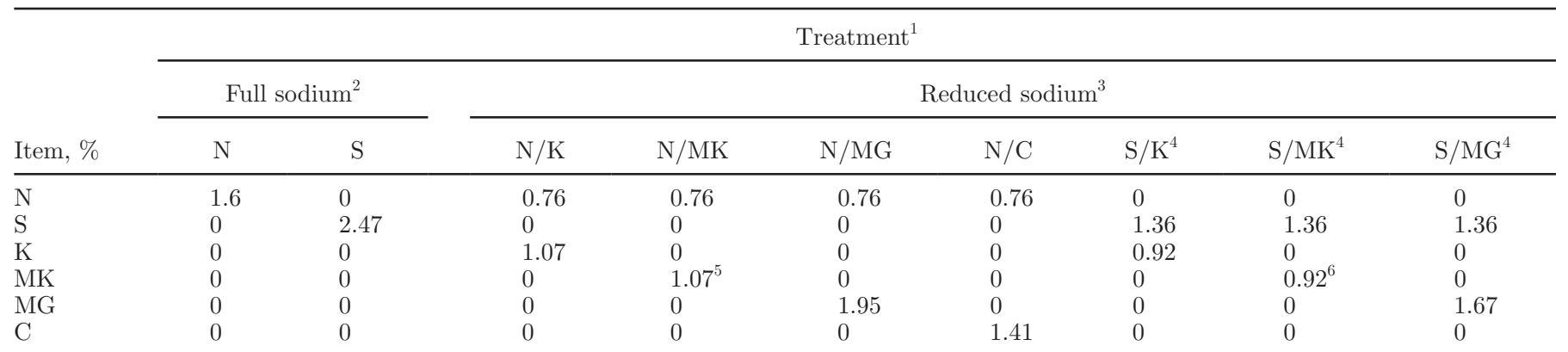

${ }^{1}$ Treatments: $\mathrm{N}=$ sodium chloride; $\mathrm{S}=$ sea salt; $\mathrm{K}=$ potassium chloride; $\mathrm{MK}=$ modified $\mathrm{KCl} ; \mathrm{MG}=$ magnesium chloride hexahydrate; $\mathrm{C}=$ calcium chloride dihydrate.

${ }^{2}$ Full sodium: $640 \mathrm{mg}$ of sodium/100 g of sample target.

${ }^{3}$ Reduced sodium: $300 \mathrm{mg}$ of sodium/100 g of sample target.

${ }^{4}$ Treatment not tested in model cheese system.

${ }^{5}$ Value based on $\mathrm{K}$ concentration in $\mathrm{N} / \mathrm{K}$ treatment.

${ }^{6}$ Value based on $\mathrm{K}$ concentration in $\mathrm{S} / \mathrm{K}$ treatment.

by atomic absorption spectrometry using a Perkin Elmer AAnalyst 100 spectrometer (PerkinElmer Inc., Waltham, MA) using IDF method 119:2007(E) (IDF/ ISO, 2007) with the exception that the hot-plate digestion method of Kira and Maio (2004) was used. The butter and flour used in model systems were analyzed for mineral content on an inductively coupled plasma atomic emission spectrometer (Optima 3000, Perkin Elmer Inc.) following AOAC method 985.01 (AOAC, 1990).

\section{Statistical Analysis}

Cheese making was replicated, and measurements of the cheese were duplicated at minimum. Linear mixed model was performed, and least significant difference was used as a summary test (SPSS Statistics ver. 17.0.2;
IBM SPSS, Chicago, IL). In the case of varying standard error between treatments, the largest is reported.

\section{RESULTS AND DISCUSSION}

Predicted salt and salt replacer levels for use in the model systems are shown in Table 1 . In the model cheese system testing, deviation of $\mathrm{a}_{\mathrm{w}}$ from the $\mathrm{N}$ control treatment was measured in the $\mathrm{N} / \mathrm{MG}, \mathrm{N} / \mathrm{C}$, and $\mathrm{S}$ treatments. These differences were most likely due to a variation in the salts from the labeled composition. Factoring in the differences into Raoult's law and retesting, the salt and salt replacer concentrations resulting in equal $a_{w}$ are shown in Table 2. The measured $a_{w}$ of the model systems were lower than the predicted 0.974 (Table 3). To evaluate the effect of solutes from the flour and butter, Raoult's law, using values from Table

Table 2. Concentrations of salt and salt replacers to create reduced-sodium model cheese with the same water activity as full-sodium model cheese containing only sodium chloride

\begin{tabular}{|c|c|c|c|c|c|c|}
\hline \multirow[b]{3}{*}{ Item, \% } & \multicolumn{6}{|c|}{ Treatment $^{1}$} \\
\hline & \multicolumn{2}{|c|}{ Full sodium ${ }^{2}$} & \multicolumn{4}{|c|}{ Reduced sodium $^{3}$} \\
\hline & $\mathrm{N}$ & S & $\mathrm{N} / \mathrm{K}$ & $\mathrm{N} / \mathrm{MK}$ & $\mathrm{N} / \mathrm{MG}$ & $\mathrm{N} / \mathrm{C}$ \\
\hline $\mathrm{N}$ & 1.6 & 0 & 0.76 & 0.76 & 0.76 & 0.76 \\
\hline S & 0 & $2.13^{4}$ & 0 & 0 & 0 & 0 \\
\hline $\mathrm{K}$ & 0 & 0 & 1.07 & 0 & 0 & 0 \\
\hline MK & 0 & 0 & 0 & 1.07 & 0 & 0 \\
\hline MG & 0 & 0 & 0 & 0 & $2.48^{4}$ & 0 \\
\hline $\mathrm{C}$ & 0 & 0 & 0 & 0 & 0 & $1.63^{4}$ \\
\hline
\end{tabular}

${ }^{1}$ Treatments: $\mathrm{N}=$ sodium chloride; $\mathrm{S}=$ sea salt; $\mathrm{K}=$ potassium chloride; $\mathrm{MK}=$ modified $\mathrm{KCl} ; \mathrm{MG}=$ magnesium chloride hexahydrate; $\mathrm{C}=$ calcium chloride dihydrate.

${ }^{2}$ Full sodium: $640 \mathrm{mg}$ of sodium/100 g of sample target.

${ }^{3}$ Reduced sodium: $300 \mathrm{mg}$ of sodium/100 g of sample target.

${ }^{4}$ Value differed from the calculated value and was modified as a result of testing in the model system. 
Table 3. Comparison of measured water activity $\left(\mathrm{a}_{\mathrm{w}}\right)^{1}$ between model systems and pilot plant-produced Cheddar cheese

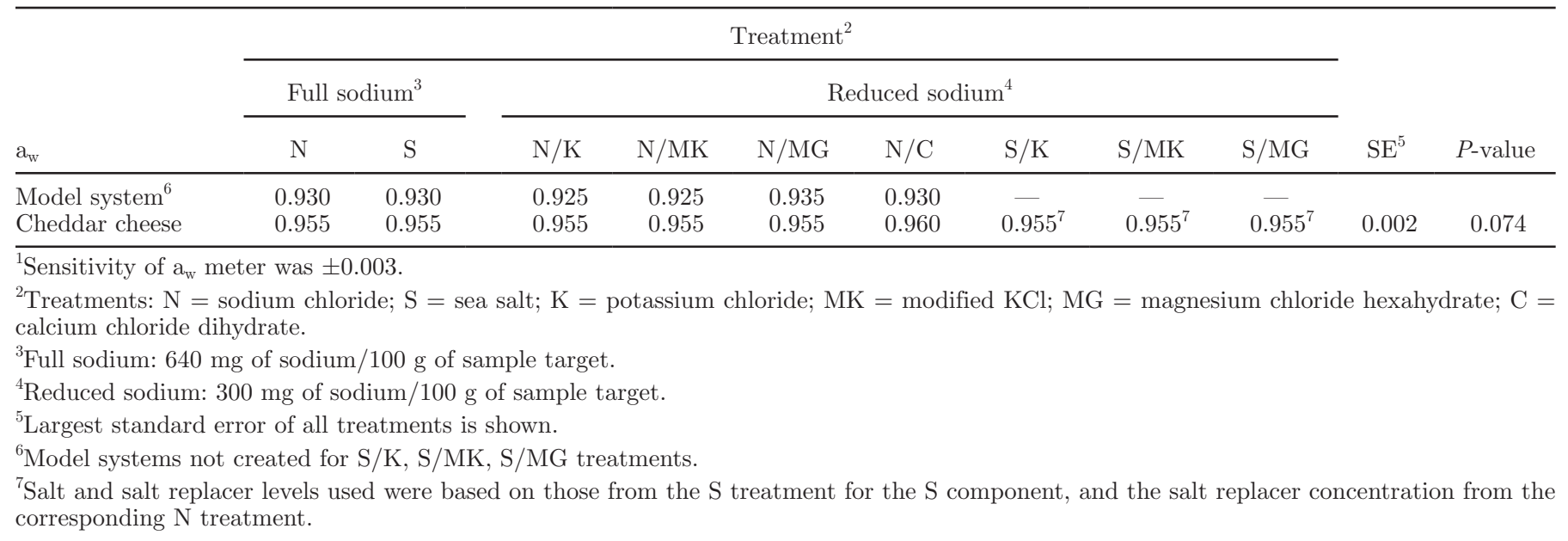

1 and the mineral content data from flour and butter, showed that the additional solutes did not account for the difference; $\mathrm{a}_{\mathrm{w}}$ was only lowered by 0.001 to 0.002 in all models. Raoult's law allows for an activity coefficient because it is expected that systems will vary from ideality. Deviation from ideality, and therefore deviation from an activity coefficient of 1 , can result from water-solute interactions and a difference in solute size compared with the size of the water molecule (BarbosaCanovas et al., 2007). The observed difference is likely a result of the activity coefficient of the model system being different from 1 .

Despite the discrepancy between predicted and observed $\mathrm{a}_{\mathrm{w}}$ in the model systems, the described method was able to determine appropriate concentrations of salt and salt replacers to produce reduced-sodium cheeses with $\mathrm{a}_{\mathrm{w}}$ equal to a full-sodium target. The $\mathrm{a}_{\mathrm{w}}$ of the manufactured cheeses was higher than that of the model systems (Table 3). This discrepancy did not limit the effectiveness of the model system method.
Composition data in Table 4 reveal that differences in syneresis occurred during salting, as evidenced by varying moisture values. However, a positive correlation was observed between moisture and sodium concentration, leading to $\mathrm{S} / \mathrm{M}$ ratios between the reducedsodium cheeses that were nearly equal. This explains why differences in the moisture levels did not lead to varying $a_{w}$.

It is likely that this model system could be used to determine concentrations of other solutes used in cheese making to yield equivalent $\mathrm{a}_{\mathrm{w}}$, such as acids. This would be useful when trying to predict changes to cheese making procedures to create equivalent $\mathrm{a}_{\mathrm{w}}$.

\section{CONCLUSIONS}

Reduced-sodium Cheddar cheeses with various salt and salt replacer concentrations were manufactured that yielded $\mathrm{a}_{\mathrm{w}}$ equivalent to those of the existing fullsodium Cheddar cheese produced at the University

Table 4. Composition and $\mathrm{pH}$ of pilot plant-produced Cheddar cheese

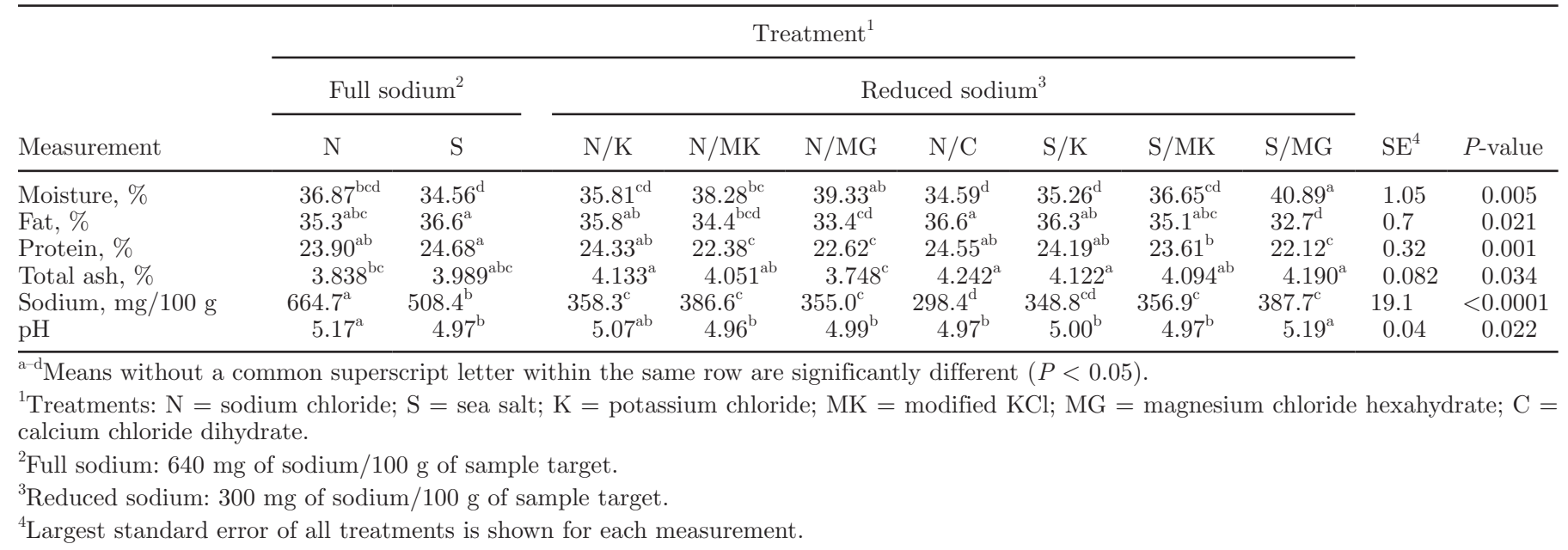


of Minnesota's pilot plant. The described method of using Raoult's law and verification with a model was a valuable tool for determining the appropriate salt and salt replacer concentrations before cheese making. Additionally, the model system was used to determine the concentrations of salt replacers when prediction by Raoult's law was not possible (when percentage quantities of each solute in the ingredient were unknown). A reference $\mathrm{a}_{\mathrm{w}}$ of 0.974 was calculated based on a cheese salt content of $1.6 \%$ and moisture of $36.8 \%$. These values can be altered to represent a cheese maker's existing "gold standard" cheese recipe. Without the model system, it would be necessary to manufacture experimental batches of cheese to determine the salt and salt replacer concentrations that produce equivalent $\mathrm{a}_{\mathrm{w}}$ to the full-sodium control. The described method of determining salt and salt replacer concentrations could be applied to many varieties of dry-salted cheese to reduce experimental time and cost.

\section{REFERENCES}

Adrogué, H. J., and N. E. Madias. 2007. Mechanisms of disease: Sodium and potassium in the pathogenesis of hypertension. N. Engl. J. Med. 356:1966-1978.

Agarwal, S., D. McCoy, W. Graves, P. D. Gerard, and S. Clark. 2011. Sodium content in retail Cheddar, Mozzarella, and process cheeses varies considerably in the United States. J. Dairy Sci. 94:16051615 .

Aly, M. E. 1995. An attempt for producing low-sodium Feta-type cheese. Food Chem. 52:295-299.

AOAC. 1990. Official Methods of Analysis. 15th ed. AOAC, Arlington, VA.

Barbosa-Canovas, G. V., A. J. Fontana Jr., S. J. Schmidt, and T. P. Labuza. 2007. Pages 109-129, 396-397 in Water Activity in Foods: Fundamentals and Applications. Blackwell Publishing, Oxford, UK.

FDA. 2011. Nutrition labeling of food. Code of Federal Regulations 21CFR101.9(c)(9). http://www.accessdata.fda.gov/scripts/cdrh/ cfdocs/cfcfr/CFRSearch.cfm?fr=101.9.

Fitzgerald, E., and J. Buckley. 1985. Effect of Total and Partial Substitution of Sodium Chloride on the Quality of Cheddar Cheese. J. Dairy Sci. 68:3127-3134.

Grocery Manufacturers Association. 2008. Sodium and Salt: A Guide for Consumers, Policymakers and the Media. Grocery Manufacturers Association, Washington, DC.

Guinee, T. P. 2004. Salting and the role of salt in cheese. Int. J. Dairy Technol. 57:99-109.
IDF/ISO. 2007. Milk and milk products-Determination of sodium, potassium, calcium and magnesium contents-Method by flame atomic absorption spectrometric method. Joint Standard IDF 119/ISO 8070. International Dairy Federation, Brussels, Belgium, and International Standards Organisation, Geneva, Switzerland.

Jacobson, M. F. 2005. Salt: The Forgotten Killer. Center for Science in the Public Interest, Washington, DC.

Katsiari, M. C., E. Alichanidis, L. P. Voutsinas, and I. G. Roussis. 2001. Proteolysis in reduced sodium Kefalograviera cheese made by partial replacement of $\mathrm{NaCl}$ with $\mathrm{KCl}$. Food Chem. 73:31-43.

Katsiari, M. C., L. P. Voutsinas, E. Alichanidis, and I. G. Roussis. 1997. Reduction of sodium content in Feta cheese by partial substitution of $\mathrm{NaCl}$ by $\mathrm{KCl}$. Int. Dairy J. 7:465-472.

Kira, C. S., and F. D. Maio. 2004. Comparison of partial digestions procedures for determination of $\mathrm{Ca}, \mathrm{Cr}, \mathrm{Cu}, \mathrm{Fe}, \mathrm{K}, \mathrm{Mg}, \mathrm{Mn}, \mathrm{Na}$ $\mathrm{P}$, and $\mathrm{Zn}$ in milk by inductively coupled plasma-optical emission spectrometry. J. AOAC Int. 87:151-156.

Lawrence, R. C., J. Gilles, and L. K. Creamer. 1993. Cheddar cheese and related dry-salted cheese varieties. Pages 1-38 in Cheese: Chemistry, Physics and Microbiology. Vol. 2. 2nd ed. P. F. Fox, ed. Chapman \& Hall, New York, NY.

Lewicki, P. P. 1997. Water sorption isotherms and their estimation in food model mechanical mixtures. J. Food Eng. 32:47-68.

Lewicki, P. P. 2009. Data and models of water activity. II: Solid foods. Pages 68-151 in Food Properties Handbook. 2nd ed. M. Rahman, ed. CRC Press, New York, NY.

Lindsay, R. C., S. M. Hargett, and C. S. Bush. 1982. Effect of sodium/ potassium (1:1) chloride and low sodium chloride concentrations on quality of Cheddar cheese. J. Dairy Sci. 65:360-370.

NYCHealth. 2011. Cutting Salt, Improving Health. Vol. 2011. The City of New York, New York.

Rahman, M., and S. S. Salani. 2009. Water activity measurement methods of foods. Pages 9-32 in Food Properties Handbook. 2nd ed. M. Rahman, ed. CRC Press, New York, NY.

Reddy, K. A., and E. H. Marth. 1995. Microflora of Cheddar cheese made with sodium-chloride, potassium-chloride, or mixtures of sodium and potassium-chloride. J. Food Prot. 58:54-61.

Richardson, G. H. 1985. Standard Methods for the Examination of Dairy Products. 15th ed. American Public Health Association, Washington, DC.

Roa, V., and M. S. Tapia. 1998. Estimating water activity in systems containing multiple solutes based on solute properties. J. Food Sci. 63:559-564.

Taormina, P. J. 2010. Implications of salt and sodium reduction on microbial food safety. Crit. Rev. Food Sci. Nutr. 50:209-227.

USDA. 2011. National Nutrient Database for Standard Reference. USDA Agricultural Research Service Nutrient Data Laboratory. Accessed Jan 28, 2011. http://www.nal.usda.gov/fnic/foodcomp/ search/.

Wehr, H. M., and J. F. Frank. 2004. Standard Methods for the Examination of Dairy Products. 17th ed. American Public Health Association, Washington, DC. 